\title{
DE ECONOMISCHE BETEEKENIS VAN DE AFSLUITING EN DROOGLEGGING DER ZUIDERZEE
}

\author{
DOOR \\ H. C. VAN DER HOUVEN VAN OORDT, MET MRDEWERKING VAN \\ Mr. G. VISSERING.
}

Met zeer groote bekwanmheid heeft de onvermoeide voorstander van de droogmaking der Zuiderzee, de Heer van der Houven van Oordt, te samen met den Heer Mr. Vissering, het genoemde onderwerp op nieuw behandeld in een boekdeel van 220 pagina's. Dat boek zou in staat zijn den meest ongeloovige tot een warm voorstander te bekeeren. Ofschoon ik behoorde tot de leden der hieronder verinelde Staatscommissie, die oın financiëele bezwaren tegen de conclusie van het Rapport steınden, zoo belet dit niet, dat ik ten volle waardeer de groote verdiensten van de plannen uit een technisch oogpunt, en den ijver waarmede de voorstanders de droogmaking bepleiten. Wegens hel groote belang der zaak meen ik dat het goed is, op een en ander uit bovenvermeld werk de aandacht te vestigen.

Zooals men weet was door de Zuiderzee-Vereeniging, en wel specinal door den tegenwoordigen Minister van Waterstaat, een plan van de droogmaking gemaakt. Dat plan was onderworpen an het oordeel van een Staatscommissie, die daarover in 1894, een rapport heeft uitgebracht.

Het project was tweeledig, eensdeels met een afsluitdijk, tusschen Noord-Holland en Friesland, anderdeels zonder afsluitdijk. Aan het eerste plan gaf de Commissie den voorkeur. Lir zouden vier groote polders komen, beschermd door dijken, waardoor men ruim 192.000 H.A. vruchtbaar, verkoopbaar land zou krijgen. Het maken van den afsluitdijk zou negen jaar vorderen; het geheele werk zou in 36 jaar 
gereed zijn. $\mathrm{Na}$ het $17^{\mathrm{e}}$ jaar zou men jaarlijks ea 10.000 H.A. moeten verkoopen of uitgeven.

Eeuparig meende de Commissie, dat, wanueer tot de uitvoering beslnten werd, de Staat dit moest doen. En de groote meerderheid der Commissie (21 van de 27 leden) meende: "dat de vraag of afsluiting en droogmaking van de Zuiderzee "op een wijze, als door de Zuiderzee-Vereeniging is voorge"steld, in 's lands belang behoort te worden ondernomen", behoudens eenige wijzigingen, bevestigend moest worden beantwoord.

Volgens het oordeel van de meest bevoegde personen verdient het rapport der Staatscommissie volledig vertrouwen, wat betreft de geprojecteerde werken, terwijl die Commissie meende zich met gerustheid te mogen nederleggen bij het resultaat van de onderzoekingen, door de Zuiderzee-Vereeniging, en reeds vroeger, ingesteld naar den aard van de gronden, die na de droogmaking te voorschijn zullen komen. De deskundigen in die Commissie meenden ook, dat die gronden roor het grootste gedeelte tot de allervruchtbaarste zullen behooren.

De schrijvers van bovenvermeld boek meenen 1), dat die gronden het meest overeen zullen komen met die van de Provincie Leeland, die c. 177.000 H.A. bedragen, en wat de vruchtbaarheid betreft met die van de IJpolders, welke 40 d 50 Hectoliter tarwe per Hectare opbrengen, en na 25 jaar nog met $f 100$ d $f 125$ per Hectare pacht betaald worden. Aan een taxatie van de vermoedelijke verkoopwaarde van de Zuiderzee polders na de droogmaking hebben de deskundigen in de Staatscommissie zich niet durven wagen. Trouwens dit is niet wel doenlijk voor terreinen, die men eerst na 17 jaren zal gaan verkoopen, en warvan dan gedurende 20 jaar elk jaar circa 10.000 H.A. aan de markt zullen komen.

Over de wijze, waarop de gronden na de droogmaking aan den man gebracht moeten worden is indertijd in de Staatscommissie zeer uitvoerig gedebatteerd, zooals ook uit haar Rapport blijkt. De Sch. resumeeren dit nog eens. Terecht meende de Staatscommissie, dat er verschillende manierea van uitgifte der gronden moesten worden toegepast, zoowel in het belang

1) Pag. $23-\tilde{0}$. 
van den Stant, om behoorlijk zulk een groote kwantiteit land te platsen, als in 't belang van den boerenstand zelf, zóó dat ook minder bemiddelden gelegenheid zouden hebben, grond te krịgeu. De Schrijvers zeggen ' /, dat ook "de eerlijke en goede arbeider" daarvoor in aaumerking moet komen; en verder ${ }^{2}$ ), dat het doel moet zijn "deu grond uit te geven aan kundige "en krachtige arbeidszonen [?], die door inspanning zich lang"Zamerhand finantieel en economisch onafhankelijk maken... "Door het land te geven in handen van kleine gebruikers, zal "men een talrijken eigengeërfden boerenstaud kunnen scheppen, " ook uit diegenen bestaande, die anders geen uitzicht hebben "daarin plaats te krijgen." Zeker wordt daarmede niet bedoeld, dat ook de geheel onbemiddelde arbeider kleine stukjes grond zou moeten krijgen. Dit laatste zou een onbegonnen werk zijn bij de plaatsing van zooveel dnizende hectaren, ook al zou, zooals geopperd is, voor dit groote werk een afzonderlijke nfdeeling aan het Ministerie van Binnenlandsche Zakeu gemaakt worden, dat als $Z$ uiderzeedepartement het werk der droogmaking behandelde.

De Sch. willen, zonder andere middelen tot realisatie uit te sluiten, dat ook deze zal toegepast worden ${ }^{3}$ ), "verkoop met "geleidelijke afbetaling en verzekering der rechten van den "verkooper door bypothecaire insehrijving, tot zoolang de "koopsom zal zijn gekweten", zoó clat "de Stant de gronden in "eigendom aan de gegadigden [overdraagt] tegen betaling eener 'annuiteit, waarin de reute, de amortisatie en een kleine "fractie voor admininistratiekosten begrepen zijn ${ }^{4}$ ). De som "waarover de annuiteit wordt berekend moet gevonden worden "door schatting en kapitaliseering van het productief vermogen "der gronden."

Tot zoover zullen zeker velen met de Schr. medegaan. Minder, wanueer daarbij gedaan wordt hetgeen zij verder zeggen: ${ }^{5}$ ) "Het geven van voorschot voor den bou w van woningen "in het aanbevolen stelsel passend, levert bij dezen vorm van "overdracht met hypolheek oneindig minder bezwaar op dan "bij eenig ander. Men zal dit voorschot niet kunnen vermijden, "al zou men er ook een afzonderlijke credietinstelling voor in

I) p. 62 .

2) p. 65.

3) p. 70 .

1) p. 71 .

5) p. 72 . ECON. 1898. 
"het leven moeten roepen, ${ }^{1}$ ) die tegelijk aan bedrijfs"kapitaal hielp, en coöperatieven aankoop van "werktuigen en zaaizaden, alsook coöperatieven verkoop "van producten bevorderde." Wanneer men dit alles in toepassiug brengt, zal men wel gegadigden krijgen, ook onder hen die geen cent bezitten. Maar men heeft dan als verkooper hoegenaand geen zekerheid. Ik geloof niet dat iewand ter wereld zijn land op die conditie zou willen verkoopen. Met alle bescheidenheid geloof ik, dat dit een voorstel zou zijn, meer geschikt voor een volksvergadering, maar minder geschikt voor een serieuse oplossing van de moeijeljjkheid voor den Staat. Toen diergelijke, hoewel niet zoo ver strekkende, planueu in de Stantscommissie besproken werden, waren de meesten het er over eens, dat dan teu minste een gedeelte van de waarde van den grond in geld door den kooper betaald zou moeten worden, als zekerheid voor den Staat voor 't geval de gebruiker den grond niet naar behooren bebouwde. De Sch. zeggen: ${ }^{2}$ ) "de bedoeling moet daarbij ook wezen het "natiomal vermogen te vermeerderen, door de goede werk"krachten - in plaats van te zien emigreeren of onder"gaan - voor het Vaderland te behouden. Manuen met goede "handen en noesten arbeidszin, zij het dan ook met ledige "zakken, moeten die gronden mede in gebruik kuunen bekomen "tegen een billijken cijns en met de zekerheid, dat al wat zij "tot verbetering aanbrengen hunzelven ten goede komt, dat "elke penning, dien zij kumnen besparen, door hen kan wor"den aangewend tot af betaling van hunne schuld aan den "staat, zoodat zij langzamerhand eigenaar wordende van het "land dat zij ouder handen hebben, bij oppassen en vlijt de "toekomst voor zich en hunne kinderen verzekerd weten."

Verder zeggen zij ${ }^{3}$ ): "De regeering, die den moed zal "hebben de wet voor te dragen, waarbij de afsluiting en de "drooglegging van de Zuiderzee worden bevolen, en de Volks"vertegenwoordiging, die haar aanneemt, aanvaarden daarmede "zoowel tegenover de Kroon, als tegenover het Volk den "heiligen plicht, om zich niet te bepalen tot de rekening in "guldens en ceuten alleen, manr om daarnaast een audere te
1) Ik spatiëer.
2) p. 74 .
3) p. 76 . 
"openen, warrbij aan de voorziening in cle sociale bohoeften "en nooden van het Nederlandsche Volk eeu groote en ruime "plaats wordt geschonken."

Ik erken, 't is een ideale schildering; maar of 't praktisch is, betwijfel ik.

Het minst gelukkig zijn de Schr. in mijn oog dítír, waar zij (le finantieele zijde van het vraagstuk bespreken (pag. $83 \mathrm{vgg.)}$.) Vooreerst uit het oogpunt van deu Staat. Zij releveeren de groote sommen die voor de spoorregen besteed zijn; manr onbetwistbaar is het, dat dit een productieve uitgaaf voor het geheele land geweest is, ook al zou de staat daarvan geen rente trekken. Evenzoo wat voor verbetering van de waterwegen is uitgegeven. Deze alle zijn uitgaven voor het verkeer, waarvan het geheele land profiteert, waardoor het productief vermogen van het geheele land verhoogd wordt. Niet juist is ook hetgeen de S. te kennen geven (p. 38) dat ook wel eens iets gedaan mag worden voor de 6 provinciën, die het naast bij de droogmaking betrokken zijn, omdat zịj "voor het meerendeel juist niet in de eerste plaats gedeeld "hebben in hetgeen tot nog toe door den stat in die rich"ting [voor den handel] is gedaau." Zij brengen er zelfs bij te pas de circa 300 millioen, die Atjeh ons reeds gekost heeft. Verder zeggen zij, dat door het Nederlandsche volk alleen in 1897 circa 24, millioen belegd is in petroleum ondernemingen, waarin in 't geheel circa 100 millioen gestoken is; dat 16 millioen belegd is in de pandbrieven van de Northwestern Pacific Hypotheekbank, oin de stad Spokane in Noord-Amerika van de noodige gebouwen te voorzieu etc. etc. Hn dan zeggen zij: "Laat men nu eindelijk de gelegenbeid ook eens gaan "openstellen om het geld van de Natie wat uit dien wereld"handel los te maken, en dit onder Staatsgarantie met Staats"controle, binnen haar eigen grondgebied te houden, te ge"bruiken en vruchtbaar te maken." Onbetwistbaar zeker is een 3 pCt. Staatsfonds een veiliger geldbelegging dan al die genoemde zaken, en 't is misschien nuttig het geldbeleggend publiek eens daaraan te herinneren. Maar kan het de roeping van den Staat zijn, door het aanbieden van zulk een Staatsfonds het geldbeleggend publiek op een beteren weg te brengen, wanneer de rente van zulk een fonds gedeeltelijk zou komen 
uit de zakken van de belastingschuldigen? En dit zou toch het geval zijn, voor zoover de kosten van de droogmaking der 'Zuiderzee niet terug gevonden werden in het provenu van de gronden.

Met de schrijvers ben $i k$ het eens ${ }^{1}$ ), dat de jarrlijksche uitgaven van den Staat voor de nieuwe gemeenten, die in de Zuiderzee polders zullen komen, ongeveer zullen opgewogen worden roor de rijksbelastingen, die dáár geïnd zullen worden. Ook de Stratscommissie kwam tot die conclusie.

Maar nu is de groote kwestie, wat de droognaking zal kosten, en wat de gronden zullen opbrengen; m. a. w. of de Staat in de opbrengst van den grond terug zal vinden wat daarvoor uitgegeven is.

Wat de kosten van de droogmaking betreft, deze zijn zó́ nauwkeurig door de Staatscomıissie berekend (en daariu zaten bij uitstek deskundigen op dit punt), dat men m. i. daarop gerust in zee kan gaan. Een groote strijd is in die Commissie gestreden over de vraag of de droogmaking bovendien belast moet worden met rente, en ook met rente van rente. Velen meenden, dat dit niet te pas kwam, omdat dit nooit gedann is bij werken door den Stant ondernomen. Anderen meenden, dat het hier een ander geval is; dat niemand, ook niet de Stant, polders gaat droogmaken, als, na de droogmaking, de polders niet ongeveer waard zijn wat het werk gekost heeft; en dat men eeu onzuivere rekening maakt, als men bij de kosten niet berekent het renteverlies tot op den tijd, dat de gronden gerealiseerd worden.

De $S$. vermelden natuurlijk dit vraggpunt. Marar ou zelfs hen te bevredigen, die verlangen, dat rente op rente zal berekend worden, geven zij het volgeude an de haud.

Bij vroegere droogmakingen hebben de publieke kissen bijdragen gegeven. ${ }^{2}$ ) Dit bedroeg 0 . a. bij de Haarlemmermeer f 250 ; bij de Alexanderpolders f 300 per H. A. Daarom willen de $\mathrm{S}$. dat hier f 325 per H. A. door den Staat a fonds perdu worden gegeven. Er zullen komen 192.500 H. A. verkoopbaar land. De Staat moet dus bijdragen $192.500 \times f 325$ is

\footnotetext{
1) p. 95 rgg.

) p. 43.
} 
f 62.562.500. Het geheele werk zal 33 jaar duren. Zij willen nu, dat de Staat, vau het eerste jaar af, elk jaar daarvoor $\frac{1}{33}$ ste zal bijdragen of $f 1.895 .835$ 's jaars. Wanneer dus volgens de Staatscommissie in het eerste jaar noodig is voor het werk f 6.500.000, dan moet daarvan f 1.895 .835 gebracht worden op het builget als uitgaaf à fonds perlu, dat uit de gewone inkoinsten hestredeu wordt, en het restant $\int 4.604 .165$ op de Zuiderzee. Het tweede jaar van de benoodigde 16.000 .000 weder f 1.895.835 onder de gewone uitgaven, en f 4.104.165 op de Zniderzec, enz. Verder willen de S. de Zuiderzee belasten met rente op rente it 3 pCt., in plats van $3 \frac{1}{2}$ zooals de Staatscommissic berekend had. Zij komen tot de slotsom, als de grouden dooreen opbrengen f 950 per H. A., op de tijdstippen van verkuop, door de Staatscommissie daarvoor gesteld, dat dan de geheele ouderneming den Staat niets kost, natuurlijk behalve die bijdragen van circa 19 ton 's jaars gedurende 33 jaar, uit de gewone Staatsinkomsten ').

Ik neem natuurlijk aan, dat de becijfering, die door een deskundige gemaakt is, juist is. En din is de opstelling werkelijk ingenieus gevonden, om het eventneel verlies voor den Staat niet zoo afschrikkend te maken.

Rekent men geen rente op rente, Inaar alleen reute, dau zou de H. A. moeten opbrengen $\mathrm{f} 835$; rekent men in 't geheel geen reute f 657 . Zonder subsidie en zonder rente zou het zijn f 982. ${ }^{2}$ )

On het overzicht gemakkelijk te maken kan men stellen als volgt.

De gemiddelde kostprijs per H. A. is :

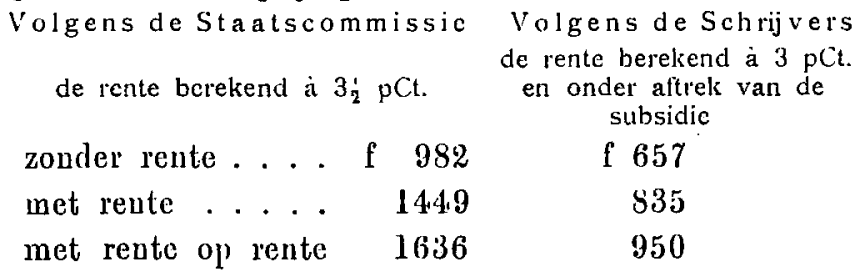

1) De S. rekenen aldus. Zij belasten de Z. V. elk jaar met de geheele uitgaaf; rekenen claarvan rente op rente tot het $34^{\text {ste }}$ jaar; crediteeren daarentegen de $Z$. V. elk jaar met een bijdrage van den Staat, en later met het provenu van de gronden, en rekenen daarop ook interest op interest in het credit der onderneming. Dit is, in andere woorden, hetzelfde wat ik boven angaf.

2) p. 52 . 
Met stilzwijgen moest ik eigeulijk voorbijgaan het onpraktisch plan vau den Sch. ${ }^{1}$ ) om ann de iuleggers vau de Postsparrbank, die daarmede genoegon nameu, te laten geven tegen de door hen ingelegde gelden Zuiderzee 3 pCt. obligatien van $\mathrm{f} 50$ of f 100 aan toonder. De Sch. willen dit doen om de geldmarkt niet te drukkeu met de jaarlijks bevoodigde millioenen voor de droogmaking. Maar dit latste is een zeer ondergeschikt bezwaar, want de zes millioen 's jaars, die noodig zullen zijn, ziju geen zoo groot bedrag, dat dit op de geldmarkt zal drukken. $\mathrm{Zij}$, die hun geld in de Postsparbank breugen, behooren tot eeu geheel andere soort personen, als die, van wie de millioenen komen, welke jaarlijks voor Stratsleeningen gevraagd zouden worden. En wanneer er onder de spararders waren die hun geld in Startsfondsen willen beleggen, dan bestatat er voor lien meer dan voldoende gelcgenheid; zij zullen niet tegen lager rente onze Staatsfondsen koopen, oundat dit geld besteed wordt voor droogmaking der Zuiderzee.

De vraag blijft echter bestaan, of die opbrengst van $\mathrm{f} 950$ per H.A. zal verkregen wordeu. Zooals ik boven zeide, de deskundigen liebben geen positief oordeel durven nitspreken, ondat de verkoop over 36 jaar loopt, en bovendien zoo verbazend veel factoren, die niet te voorzien ziju, daarop zullen influenceeren.

Bij de bespreking van de vermoedelijke opbrengst der drooggemaakte gronden zijn door de Staatscommissie en ook door de Sch., terecht, vergelijkingen gemaakt met de verkoopwaarde van soortgelijke gronden. Maar met bescheidenheid geloof ik, dat daarbij niet genoeg in het oog is gehouden, dat bouwland, gelegen in of nabij bevolkte streken, heel wat meer aantrekkelijkheid heeft dan land, dat gelegen is in een betrekkelijk onbebouwde streek, zooals het dikwijls uitgedrukt wordt, "aan het einde van de wereld". Daarbij komt, dat zulk een streek zeker in de eerste jaren geen gezonde streek genoemd kan worden. In de Staatscommissie is ook in het breede gesproken, over de productieve waarde; er is uitgerekend, wat die grond aan verschillende gewassen zal kunnen opbrengen, en wat dus de kapitaalwaarde zal zijn. Naar de aldus opge-

1) p. 55 . 
maakte berekeningen zouden prïzen van boven de $\mathrm{f} 1000$ per H.A. eigenlijk veel to laag zijn, ook al neemt men aan; dat de graanprijzen niet zullen stijgen. Van harte zou ik wenschen dat die voorspelling bewaarheid werd.

De voorstanders der droogmaking meenen, dal een auder geldelijk voordeel ten bate der ouderneming in anmerking genomen moet worden, namelijk de voordeelen die de omliggende Provinciën en Waterschappen door het werk zullen hebben, te weten de mindere kosten die zij zullen hebben voor de dijken, die, in plaats van zeedijken, binnendijken zullen worden; de verbeterde afwatering van de nu in de Zuiderzee uitloopende rivieren; let voordeel dat Friesland zoet water kan inlaten enz. enz. ') Die financiëele voordeelen zullen zeer zeker voor de Povinciën ontstaan; maar die zullen de kosten van het werk niet verminderen voor de u Stant: want waarchijnlijk zullen de Provinciën niet genegen zijn op grond daarvan, een deel vall de kosten te betalen. Ook in de Staatscommissie is dit punt uitvoerig besproken in denzelfden geest. Dat de defensie verbeterd wordt ${ }^{2}$ ) is wel iets dat in anumerking genomen unag worden.

Heb ik op het eerste gedeelte van het werk van de schrijvers mij eenige aanmerkingen veroorloofd, met instemming daarentegen meen ik dat velen zullen lezen wat zij verder zeggen ${ }^{3}$ ) over de gevolgen van het werk voor de economische toestanden ten opzichte van : $1^{\circ}$. Bevolking en loonen $; 2^{\circ}$. Grondwaarde; $3^{\circ}$. Landpachten; $4^{\circ}$. Productieprijzen, en 5 '. Landbouw-toestanden in 't algeineeu. Een reeks van zeer belangrijke gegevens zijn hier bijeenverzaneld, waruit men zien kan, dat het voor ous land een groot voordeel zon geven, als die terreinen in cultuur gebracht werden, ook al zou die droog-

1) Zie p. 28 en 37. De Nationale Zuiderzee-Bond heeft een onderzoek naar die indirecte voordeelen ingesteld, en kumt tot de slotsom, dat voor die verschillende belangen $f 1.055 .000$ 's jaars worden uitgespaard, hetgeen gekapitaliseerd tegen $4 \mathrm{pCt}$. een kapitaal vertegenwoordigt van 25 millioen. Bovendien behoeven dan verschillende werken ten bedrage van $f 1.185 .000$ niet uitgevoerd te worden. Van de $\mathrm{f} 40.500 .00$, waarop de $\Delta$ fsluitdijk geraamd is, blijven dus slechts 14 millioen over.

2) p. 32 .

3) p. 105 . 
making aan den $S_{\mp}$ at ecnige geldelijke opofferingen kosten. Naar de bovenstanando gegevens te ourdeelen zijn er op 100 H.A. bouw- en grasland 20 arbeiders en 80 niet arbeidende inwoners '); op elke 10.000 H.A. die jaarlijks wa de droogmaking an den man komen, vindeu dus telkens 10.000 inwoner's eeu bestaan. En in de laatste 8 jaren is de bevolking van Nederland jaarlijks met 50.000 à 70.000 personen toegenomen. De jairrlijksche ounzet van landelijke eigendommen bedroeg in $1890 / 1$ en $1893 ; 4,38$ en 45 millinen ${ }^{2}$ ). De 10.000 H.A. die jaarlijks vau de Zuiderzee verkocht moeten wordeu bedragen à 950 per H.A. $9 \frac{1}{2}$ millioen; maar daarvan zal een gedeelte wel op erfpacht of op andere wijze tegen een jararlijksche retributie geplaatst worden. De daling van den prijs voor de kleigronden, zoowel voor boerderij als veehouding heefti valu 1882 tot 1896 slechts bedragen 6 pCt. ${ }^{3}$ ) Volgens ouderzockingen van den heer A. Venema (zie Bconomist Nov.-Dec. 1897) was de gemiddelde opbrengst in 1893

$$
\begin{aligned}
& \text { vau kleigrond-bouwland f } 1556 \text { per H.A. } \\
& \text { " zaudgrond-bouwlaud } 809 \text { " " }
\end{aligned}
$$

Volgens onderzoekiugen van de (ommissie voor de Slatistiek *) zijn de pachtprijzen voor kleigrond-bouwland geweest gewiddeld :

$$
\begin{array}{lr}
1882 / 6 & \text { f } 64.76 \\
1887 / 91 & 60.87 \\
1892 / 6 & 59.87
\end{array}
$$

De Schrijvers meenen, dat de opbrengst van de Zuiderzeegronden veel hooger zal zijn, omdat de 70.804 H.A. in ons land, die met tarwe bebouwd waren, gemiddeld $24,7 \mathrm{H} \mathrm{L}$. per H.A. opbrachten, terwijl zij meenen dat de Zuiderzee grondeu 50 H.L. kunnen opbrengen. Of dit nu niet wat sterk gekleurd is, zou ik niet durveu zeggen. In elk geval zullen niet al die gronden zooveel opbrengen, en zal er voor de verkoopwaarde, zooals ik boven zeide, in aanmerking genomen moeten worden, dat die landen zeker uninder gewild zullen zijn.

Wat de Schrijvers zeggen over den vermoedelijken loop vau de prijzen der landbouwproducten is zeer belangrijk, mar uit
1) p. 106
2) p, 116
3) p. 119 en 120.
') p. 126 : 
den aard der zaak zeer speculatief. Zij meenen dat wij aan de grens gekomen ziju van de dialing in de kosten vau vervoer van overzeesche producten ${ }^{1}$ ). Dit is zeer goed mogelijk, al is het niet waarschijnlijk; maar of wij zeker kunuen zijn, dat er niet op meer plaatseu in overzeesche gewesten voedingsmiddelen voor Europa geteeld zullen worden, zal zeker nicmand durven bevestigen. Overigens is het bemoedigend te zien ${ }^{2}$ ) lioe een keuner van de landbouwtoestanden den landhouwers woed inspreekt, en verschillende wenken geeft om hot landbouwbedrijf meer winstgevend te maken.

De S. berekeuen ") dat van de 189 millioen, waarop, algeselsejden van de renteberekening, het werk geraumd is, slechts voor c. 26 millioen an materialeu uit het huitenland zullen komen; dat voor arbeidsloon en scheepsvrachten gerckend wordt 15 millioen, zoodat er overblijft 118 millioen voor levering van materialen uit het binnenland. Hierbij kount dan nog, wat gemakkt moet worden voor scholen en audere gebouwen, noodig voor de $S$ Gemeenten ieder van 5 dorpen, dic er zullen komen, en de kosten van ambouw van de 4000 boerderijen, die men schat dat op de e. 200.000 H.A. noodig zulleu ziju. Van een en ander zal het geheele laud profiteereu. Mar de S. wijzen er op ${ }^{*}$ ), dat Arsterdam, doordien de nieuwe polders in hare onmiddelijke nabijheid komes, daardoor groot voordeel zal hebben; zij zeggen verder: "een tiende van het "Nederlandsche volk houdt verblijf en zoekt zijn bestaan iu "Amsterdam, zoodat het belang der hoofdstad bij de groote . "onderneming waarlijk wel mag worden in het oog gehouden."

Erkend wordt door de Schrijvers, dat in de naaste tockornst voor voldoening van de zoogenaamde sociale behoeften groote sommen zullen uoodig zijn. Maar zij meenen dat een uitgaaf van slechts 2 millioen 's jaars gedurende de eerste 33 jaar als subsidie voor de droogmaking niet zóó belangrijk is, dat die in den weg zal staan an hetgeen voor die andere zaken noodig is. ")

Volgens de $\mathrm{S}$. is het veel rationeeler, dat de staat zijn geld besteedt om de 'Zuiderzee droog te maken, die later jaarlijks c. 50 millioen an "te verzilveren bruto product" zal opleve-
1) p. 131.
2) p. $138-9$.
3) p. 143.
1) p. 146 .
5) p. 152 . 
ren, dan te trachten de heide tot vruchtdragend land te maken. ${ }^{1}$ )

Uit een politiek oogpunt de zaak beschouwend wijzen de Schrijvers er op, ${ }^{2}$ ) hoe alle natiën er op uit zijn, on door het stichten vau Koloniën de débouclés van haar nijverheid te vergrooten; welk een ramp het voor ons land zou ziju, als wij een provincic mocsten verlie\%en; welk ecn zegen het gerekend zou worden, als wij onze grenzen tot Oost-Pricsland konden uitbreiden; en hoe wij feitelijk door dit werk een nieuwe Provincic rijker zullen worden.

Bindelijk geveu de S. er een overzicht van, loe in de buitenlandsche bladen over de onderneming met groote ingenoheid is melding gemakt, en, eveneens bijna zonder nitzondering in den zolfden geest door de binnenlaudsche pers.

Als de plaatsruimte liet nict verbood zou ik gaarne meer dan het boveustaande hebben angehaild nit dit zoo belangrijke geschrift Het is een zakkundig, warm pleidooi, uit den ard der zaak wel wat sterk gekleurd en hier en daar wat eenzijjlig; maar tegelijk is het met zooveel geestdrift geschreven, dat het wel geschikt is om velen te overtuigen. Ik moet erkennen, dat ik voor mijzelf zou wcnschen, dat mijn finautic̈ele bezwaren waren weggenomen. Als de S. zeggen, zooals ik boven anhhalde, dat de Regeering die het plin zou voor stellen, en de Volksvertegenwoordiging, dic het zou aunnemen, daardoor zouden aanvaardeu, "den heiligen plicht om zich niet te bepalen tot de "rekening in guldens en centen alleen, maar om daaruaast "cen andere te openen, warbij aan de voorziening in de "suciale behoeften en nooden van het Nederlandsche Volk cen "groote en ruime plaats wordt geschonken;" zoo gevoel ik meer voor de laatste rekening dau voor de eerste. Maar, al is het een onangename takk dil te erkennen, ik $\mathrm{kan}$ mij wanr niet, geheel vau de fiuantic̈ele berekening losmaken.

Rotterdam, September 1898.

M. Mers.

1) p. 154 .

2) p. 169 . 